\title{
Fatal Massive Amphetamine Ingestion Associated with Hyperpyrexia
}

\author{
Mark E. Wallace, MD, MPH, and Rbonda Squires, MS, FNP
}

Amphetamine use in the 1950s, 1960s and 1970s resulted in many reports of death attributed to toxicity. Few approved indications exist for the medical use of amphetamine and its derivatives. Unfortunately, when compared with other illegal street drugs, nonmedical uses of various amphetamines have been increasing in the 1990s. The abuse of amphetamines continues to cause severe and lethal intoxications, although to a lesser extent than alcohol, which has caused more than 18,000 non-motor-vehicle-related deaths in the United States in 1997. In addition to other commonly abused substances, clinicians should suspect stimulant use, be aware of common street names (Table 1), and be prepared to recognize the characteristics most commonly associated with poisoning from this class of drugs. This brief report describes one of two recent overdose cases admitted to the inpatient service of a community hospital family practice residency program.

\section{Case Report}

A 19-year-old man was arrested after a traffic violation and taken to the local jail. He reportedly told his cellmate that he had ingested 8 "balls" $(8 \mathrm{~g})$ of methamphetamine. One and one-half hours after his arrest, the emergency medical service was called to treat him for possible withdrawal symptoms. Personnel at the scene said that the man had had no seizures, but they did witness severe rigors with diaphoresis for approximately 30 minutes. Paramedics were told that the patient was known to have a history of methamphetamine use.

Initially the patient was able to communicate with difficulty. He admitted to "one line a day" and that his last use was at least 10 hours earlier. Paramedics described the patient as red, cool, and diaphoretic, with severe shakes and incontinent of

Submitted, revised, 2 September 1999.

From North Colorado Family Medicine (MEW, RS), Greeley, Colo. Address reprint requests to Mark E. Wallace, MD, MPH, 1600 23rd Avenue, Greeley, CO 80631. urine. His lungs were clear, and his respiratory rate was $60 / \mathrm{min}$. An electrocardiogram revealed a sinus tachycardia of $200 / \mathrm{min}$. Pulse oximetry on 2.5 $\mathrm{L} / \mathrm{min}$ of oxygen was $91 \%$. Whole blood glucose was $81 \mathrm{mg} / \mathrm{dL}$.

On arrival at the emergency department, the patient's rectal temperature was greater than $108^{\circ} \mathrm{F}$, respirations were $45 / \mathrm{min}$, pulse was 180 beats per minute, blood pressure was $186 / 96 \mathrm{~mm}$ $\mathrm{Hg}$. Pulse oximetry on $10 \mathrm{~L} / \mathrm{min}$ of oxygen was $98 \%$ saturated. The patient displayed diffuse rigidity and tremulousness, his skin was hot and diaphoretic, his pupils were dilated, normal doll's eyes were present, and he did not respond to verbal or painful stimuli. A Foley catheter returned minimal urine output.

Ice packs on the patient's groin, axillae, and neck lowered his temperature to $105.5^{\circ} \mathrm{F}$. During resuscitation efforts he received sequential trials of lorazepam, labetalol, and $50 \%$ dextrose in water. His blood pressure decreased to $86 / 44 \mathrm{~mm} \mathrm{Hg}$. After a trial of lidocaine for his tachycardia, the patient's heart rate decreased to 140 beats per minute. Intravenous normal saline was rapidly infused. His respiratory status worsened, and pulse oximetry dropped to $63 \%$ saturation on $10 \mathrm{~L} / \mathrm{min}$ of oxygen. He was intubated orally with difficulty because of teeth clenching. Gastric lavage produced a string, but there were no pill fragments. Sorbitol and activated charcoal were administered, and the patient was given intravenous famotidine. A rectal examination showed no pill fragments or other foreign bodies. No overt track marks were found. A chest radiograph was negative, as was computed axial tomography of the head. An electrocardiogram continued to show sinus tachycardia. Initial chemistry and coagulation laboratory values were all essentially normal. Arterial blood gases indicated metabolic acidosis.

The patient was transferred to the critical care unit 3 hours after his arrest by police, when it is presumed that he had swallowed the 8 "balls" to avoid detection. A drug-screening test of blood 
Table 1. Common Street Names for Various Amphetamines.

\begin{tabular}{ll}
\hline Amphetamine & $\begin{array}{c}\text { Common } \\
\text { Street Name }\end{array}$ \\
\hline Methamphetamine & Speed \\
& Ice \\
Crank \\
Crystal \\
& Go \\
3,4-methylenedioxymethamphetamine & Ecstasy \\
(MCMA) & E \\
& Adam \\
& XTC \\
& M\&M \\
3,4-methylenedioxyethamphetamine (MDEA) & Eve \\
3,4-methylenedioxyamphetamine (MDA) & Love drug \\
\hline
\end{tabular}

drawn 8 hours after admission was negative for alcohol. Cannabinoids were present. His blood was positive for amphetamines, with a serum value of $3,500 \mathrm{ng} / \mathrm{mL}(3.5 \mathrm{mg} / \mathrm{L})$. Dantrolene was prescribed for temperatures of $104^{\circ} \mathrm{F}$ and higher. Temperature decreased to $103.6^{\circ} \mathrm{F}$ with cooling measures and the paralytic. The patient remained comatose with a Glasgow coma scale score of 3 . He began to ooze blood from various orifices. His fibrinogen decreased from $128 \mathrm{mg} / \mathrm{dL}$ to $85 \mathrm{mg} / \mathrm{dL}$ during the first 14 hours. His blood urea nitrogen and creatinine levels were first elevated on day 2 of hospitalization. His aspartate aminotransferase (AST) level was elevated to $1,927 \mathrm{U} / \mathrm{L}$, and his urine became positive for myoglobin.

The patient's liver function tests continued to worsen from day 2, with enzyme levels reaching their highest on day 4 at an AST level of 4,422 U/L and alanine aminotransferase (ALT) of 2,786 U/L. The transaminase levels subsequently decreased rapidly with a delayed increase in total bilirubin. Serum creatine kinase levels exceeded $20,000 \mathrm{U} / \mathrm{L}$ on day 2. Blood gas measurements showed a mixed acid-base disorder with a metabolic alkalosis and anion gap metabolic acidosis. His platelet count decreased to $28,000 / \mu \mathrm{L}$ by day 3 . His oxygen needs increased as he moved into adult respiratory distress syndrome. Dialysis was begun on day 4 . His neurologic status never improved during hospitalization. Multiple cardiac arrests occurred. The patient continued to spike temperatures, despite infectious disease evaluation, antibiotic adminis- tration, and aggressive cooling measures, until his death from an asystolic cardiac arrest on day 16.

\section{Discussion}

An extensive review of the literature for the 25 years before the publication in 1963 by Zalis and Parmley ${ }^{1}$ of the 10th death attributed to amphetamine toxicity found only 9 previous fatal cases of amphetamine poisoning. By 1970 the world medical literature contained 43 reports of deaths either directly attributable to the pharmacologic actions of amphetamines or related to secondary complications from the route of drug administration. ${ }^{2}$ Visits to US emergency departments related to amphetamine use increased $250 \%$ from 4,900 encounters in 1991 to 17,400 visits in $1994 .^{3}$ During this same interval, medical examiner-reported deaths in the United States related to methamphetamine rose from 151 to 433 .,4 $^{3,4}$

The most identifiable clinical effects of amphetamines result from the release of catecholamines, especially dopamine and norepinephrine, from the presynaptic terminals. ${ }^{4}$ Common features of amphetamine toxicity include tachycardia, dysrhythmias, hypertension, hyperthermia, agitation, delirium, seizures, hyperreflexia, diaphoresis, tachypnea, and rhabdomyolysis. ${ }^{5-8}$ Death from amphetamine intoxication commonly results from hyperthermia, cardiac dysrhythmias, and intracerebral hemorrhage. $1,2,4,-6,9,10$

Management of amphetamine toxicity should start with the ABCs (airway, breathing, and circulation) when apnea, cardiac arrest, dysrhythmias, or seizures are the initial signs. ${ }^{6}$ An electrocardiogram should be obtained to look for ischemia, other drug effects, and signs of electrolyte (especially potassium) abnormalities. ${ }^{4,6}$ Continuous cardiovascular monitoring should be initiated. The use of $\beta$-adrenergic antagonists is somewhat controversial because of the potential for an exaggerated $\alpha$-adrenergic stimulation response. Instead, treatment of hypertension from psychostimulant overdose with $\alpha$-adrenergic, mixed $\alpha$ - and $\beta$-adrenergic antagonists, or nonadrenergic agents is recommended by some authors. ${ }^{6}$ Controlling temperature and agitation is critical to lowering morbidity from overdose. Sedation using benzodiazepines is clinically as effective as using the dopamine-antagonist neuroleptics, which lower seizure threshold and negatively affect temperature regulation. ${ }^{4}$ 
Temperature control should be achieved using cooling blankets, ice water gastric lavage, ice packs, or pharmacologic paralysis. Convection cooling might be appropriate to avoid the maladaptive shivering that results from other cooling measures. ${ }^{6}$ There is limited clinical experience with the use of specific D-1 receptor antagonists that appear to attenuate the lethal hyperthermic effect of amphetamines. ${ }^{6}$ Although urinary acidification can increase the elimination of amphetamines, such action is no longer recommended because of the possibility of worsening renal insult from rhabdomyolysis. It is better to promote urine output with rapid, generous intravenous fluid resuscitation and to maintain an alkaline urine to alleviate the effects of myoglobin on the kidneys. ${ }^{4,6}$ Electrolytes should be monitored and treated appropriately.

It is presumed that this patient swallowed $8 \mathrm{~g}$ (154.74 $\mathrm{mg} / \mathrm{kg}$ body weight) of methamphetamine shortly before his arrest to avoid detection of the drug by police. Gastric lavage produced a string. Other foreign bodies were never detected. Nevertheless, this overdose represents the longest survival (16 days) in a patient with such a dramatic peripheral blood amphetamine level $(3.5 \mathrm{mg} / \mathrm{L})$ with which we are familiar. A 1996 case report from the King County Medical Examiners Office documented a peripheral blood amphetamine level of $0.43 \mathrm{mg} / \mathrm{L}$ in a patient who died 5 hours after being arrested. ${ }^{11}$ The case we described was characterized by common features of psychostimulant overdose. Despite aggressive treatment, a lethal outcome could not be avoided. Clinicians should suspect this type of ingestion now that law enforcement efforts are increasingly focused on drug interdiction, and persons possessing illegal drugs take dangerous steps to avoid detection.

\section{References}

1. Zalis EG, Parmley LF Jr. Fatal amphetamine poisoning. Arch Intern Med 1963;112:822-6.

2. Kalant H, Kalant OJ. Death in amphetamine users: causes and rates. Can Med Assoc J 1975;112:299304.

3. Greenblatt JC, Gfroerer JC, Melnick D. Increasing morbidity and mortality associated with abuse of methamphetamine-United States, 1991-1994. MMWR Morb Mortal Wkly Rep 1995;44:882-6.

4. Chiang WK. Amphetamines. In: Goldfrank LR, Flomenbaum NE, Lewin NA, Weisman RS, Howland MA, Hoffman RS, editors. Goldfrank's toxicologic emergencies. 6th ed. Stamford, Conn: Appleton \& Lange, 1998.

5. Ginsberg MD, Hertzman $M$, Schmidt-Nowara WW. Amphetamine intoxication with coagulopathy, hyperthermia, and reversible renal failure. A syndrome resembling heatstroke. Ann Intern Med 1970; 73:81-5.

6. Callaway CW, Clark RF. Hyperthermia in psychostimulant overdose. Ann Emerg Med 1994;24:6876.

7. Jordan SC, Hampson F. Amphetamine poisoning associated with hyperpyrexia. Br Med J 1960;17:844.

8. Beebe DK, Walley E. Smokable methamphetamine ('ice'): an old drug in a different form. Am Fam Physician 1995;51:449-53.

9. Simpson DL, Rumack BH. Methylenedioxyamphetamine. Clinical description of overdose, death, and review of pharmacology. Arch Intern Med 1981;141: 1507-9.

10. Kojima T, Une I, Yashiki M, Noda J, Sakai K, Yamamoto $\mathrm{K}$. A fatal methamphetamine poisoning associated with hyperpyrexia. Forensic Sci Int 1984; 24:87-92.

11. Logan BK, Weiss EL, Harruff RC. Case report: distribution of methamphetamine in a massive fatal ingestion. J Forensic Sci 1996;41:322-3. 